\title{
Development of a Functionalized Xenon Biosensor
}

Megan M. Spence, ${ }^{1 * \dagger}$ E. Janette Ruiz, ${ }^{* \dagger}$ Seth M. Rubin, ${ }^{2 *}$ Thomas J. Lowery, ${ }^{* \dagger}$ Nicolas Winssinger, ${ }^{3 \|}$ Peter G. Schultz, ${ }^{\prime \prime}$ David E. Wemmer, *t and Alexander Pines $* \$ \$$

*Department of Chemistry, University of California at Berkeley, Berkeley, CA 94720, USA.

${ }^{\dagger}$ Materials Sciences and ${ }^{\ddagger}$ Physical Biosciences Divisions, Lawrence Berkeley National Laboratory, Berkeley, CA 94720, USA.

"Department of Chemistry and the Skaggs Institute for Chemical Biology, The Scripps Research Institute, 10550 North Torrey Pines Road, La Jolla, CA 92037, USA.

${ }^{\S}$ Address correspondence to this author. E-mail: pines@berkeley.edu.

Development of a Functionalized Xenon Biosensor

${ }^{1}$ Current address: ETH-Zürich, Laboratorium für Physikalische Chemie, CH-8093 Zürich, Switzerland.

${ }^{2}$ Current address: Memorial Sloan-Kettering Cancer Center 1275 York Avenue, New York, NY 10021, USA.

${ }^{3}$ Current address: ISIS, Louis Pasteur University, 8 allée Gaspard Monge, F-67000 Strasbourg, France. 


\section{Abstract}

NMR-based biosensors that utilize laser-polarized xenon offer potential advantages beyond current sensing technologies. These advantages include the capacity to simultaneously detect multiple analytes, the applicability to in vivo spectroscopy and imaging, and the possibility of "remote" amplified detection. Here we present a detailed NMR characterization of the binding of a biotin-derivatized caged-xenon sensor to avidin. Binding of "functionalized" xenon to avidin leads to a change in the chemical shift of the encapsulated xenon in addition to a broadening of the resonance, both of which serve as NMR markers of ligand-target interaction. A control experiment in which the biotin-binding site of avidin was blocked with native biotin showed no such spectral changes, confirming that only specific binding, rather than nonspecific contact, between avidin and functionalized xenon leads to the effects on the xenon NMR spectrum. The exchange rate of xenon (between solution and cage) and the xenon spin-lattice relaxation rate were not changed significantly upon binding. We describe two methods for enhancing the signal from functionalized xenon by exploiting the laser-polarized xenon magnetization reservoir. We also show that the xenon chemical shifts are distinct for xenon encapsulated in different diastereomeric cage molecules. This demonstrates the potential for tuning the encapsulated xenon chemical shift, which is a key requirement for being able to multiplex the biosensor.

\section{Introduction}

Developments of new approaches in analytical chemistry are being increasingly driven by advances and applications of combinatorial chemistry and parallel assays. Products of combinatorial syntheses require fast and sensitive screening techniques due to the production of large numbers of chemical analogues to be tested for affinity, catalytic activity, or other properties of interest. ${ }^{1-3}$ Various detection methodologies for high-throughput screening (HTS) applications, including laser-induced fluorescence, fluorescence polarization, and fluorescence energy transfer, have been implemented in high density microtiter plate format. ${ }^{4-7}$ The spatial separation of possible interacting pairs distinguishes signals from 
different ligand-target combinations, and readings are made by scanning techniques or by imaging. ${ }^{8}$ At present, particular challenges exist in the development of multiplexed assays, which allow multiple interactions in samples to be detected simultaneously.

Macromolecule-based biosensors exploit the specificity and strength of biological ligand-target interactions to selectively signal the presence of particular molecular targets. These biosensors rely on the coupling of biological recognition events to an experimental observable, allowing external detection. Historically, biosensors have been used for routine analyses in clinical diagnosis, as in the case of the traditional glucose sensor; ${ }^{9}$ however, new concepts in biosensor design are being considered for highthroughput applications such as drug discovery. ${ }^{10}$ Recent developments in biosensor technology, such as surface plasmon resonance chips, ${ }^{11}$ are already being developed in a multiplexed format. ${ }^{12}$

Nuclear magnetic resonance (NMR) is powerful in analytical chemistry applications due to its high information content. Steady progress is being made to incorporate NMR analysis into high-throughput and combinatorial chemistry applications. ${ }^{13-18}$ Utilization of conventional NMR for high-throughput biosensor applications may be limited by the intrinsically low sensitivity and the complexity of spectra obtained from biomolecules and mixtures. Laser-polarization ${ }^{19}$ of ${ }^{129} \mathrm{Xe}$ offers an increase in signal-tonoise by several orders of magnitude relative to the equilibrium nuclear-spin polarizations measured in normal NMR experiments. ${ }^{20,21}$ In addition, ${ }^{129} \mathrm{Xe}$ NMR spectra are less complex than those from ${ }^{1} \mathrm{H}$ or ${ }^{13} \mathrm{C}$ NMR, usually showing only a few, easily interpretable lines with no background signal. Despite its spectral simplicity, xenon exhibits the important property that it can sensitively report on its local environment via its chemical shift and relaxation parameters. Furthermore, xenon NMR and MRI can take advantage of "remote" detection of signals that can be used to reconstruct substantially amplified spectra $^{22}$ and images. ${ }^{23}$ NMR of ${ }^{129} \mathrm{Xe}$ has been used to investigate the structure and dynamics of materials, ${ }^{24-27}$ molecular cages, ${ }^{28-34}$ biological systems, and for biomedical applications. ${ }^{35-37}$ Recently, extensive reviews regarding the history and development of hyperpolarized xenon NMR have been published. $^{38,39}$ 
Biological systems studied with ${ }^{129} \mathrm{Xe}$ NMR include globular proteins such as myoglobin and hemoglobin, ${ }^{40-46}$ membrane associated peptides such as gramicidin, ${ }^{47}$ and lipid membranes themselves. ${ }^{48}$ While xenon shows appreciable binding to many proteins, as evidenced by its use in making heavy atom derivatives of protein crystals for $x$-ray crystallography, ${ }^{49,50}$ the xenon-protein binding constants are relatively low $\left(\mathrm{K}_{\mathrm{a}} \approx 10\right.$ to $\left.100 \mathrm{M}^{-1}\right)$. The weak binding in solution between xenon and proteins results in fast exchange of bound and free xenon, and hence NMR spectra exhibit a single resonance. The chemical shift reflects a population-weighted average over the xenon chemical shifts of the available environments: solvent, protein interior, and protein surface. As a result, the chemical shift value of this single peak can report on changes in protein interactions. Experiments with maltose binding protein demonstrated that the ${ }^{129} \mathrm{Xe}$ chemical shift responds to a change in protein conformation upon ligand binding; the difference in shift results from distinct xenon-protein interactions between the two conformers. $^{44,45}$ However, to induce measurable shifts relatively high concentrations of the 'analyte' are required.

In spite of the favorable attributes of xenon interacting with proteins in solution, high-sensitivity molecular sensing is not compatible with the fast-exchange characteristic of xenon-protein interactions. This limitation can be overcome by increasing the strength of a particular xenon interaction that reports analyte binding allowing a resonance to be resolved from those averaged into the single fast-exchange peak. To realize this, we have taken the approach of 'functionalizing' the xenon by providing a physical coupling between xenon and the ligand that targets a protein. Recently, as a proof-of-principle case, we reported a molecule designed to be an NMR biosensor that targeted the biotin-binding protein avidin. ${ }^{51}$ The sensor consists of a modified cryptophane-A cage, to which xenon binds as the NMR reporter, connected via a tether to the ligand biotin (Figure 1). The Xe NMR signal demonstrated a response to 


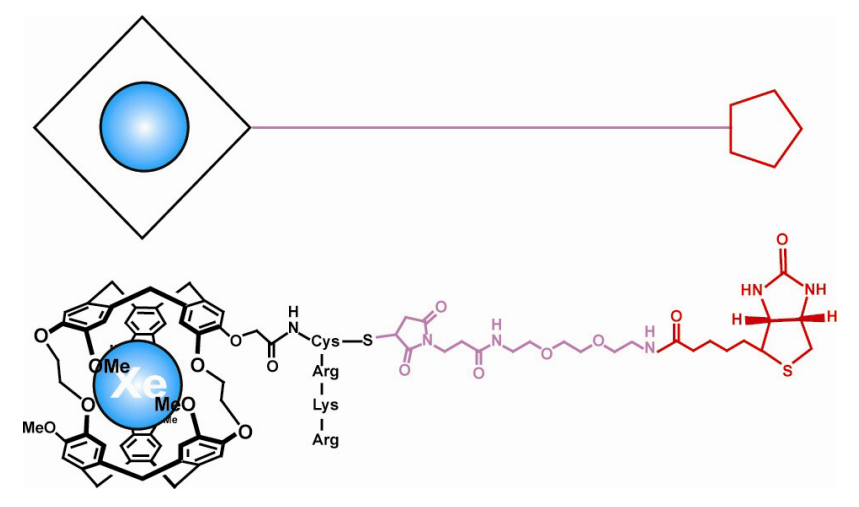

Figure 1. Structure and schematic representation of biosensor molecule designed target xenon to avidin with high affinity and specificity. Cryptophane-A (black) binds the xenon atom, and the biotin ligand (red) is connected to encapsulated xenon via a linker (purple).

the binding of the sensor to avidin in solution. The binding of xenon to cryptophane-A is sufficiently tight as to result in slow exchange; therefore, the resonance for functionalized xenon is distinct from xenon in bulk solution. The directly tethered ligand can bind to its target, with the bound xenon acting as a reporter (sensor) of this event through changes in its chemical shift and linewidth. The potential for multiplexed detection comes from the chemical shift range available in the NMR experiment. Implementation of high-sensitivity fluorescence-based systems in a direct multiplexing assay is challenging due to spectral overlap, despite the high wavelength tunability of some systems such as quantum-dot-tagged microbeads. ${ }^{52,53}$ In microarray format, realization of the xenon biosensor could result in a high density assay in which each well of the microtiter plate would not contain individual interacting pairs, but rather a single synthetic product interacting with a complete set of derivatized target molecules. Within each well, binding to different targets would be distinguishable on the basis of chemical shift.

In this work, we provide a detailed characterization of this avidin binding, functionalized-xenon system. The high sensitivity of the functionalized xenon to its environment is demonstrated by the observation that different diastereomer products of the cryptophane synthesis yield different chemical 
shifts. Upon the addition of protein, additional resonances appear in the spectrum that can be attributed to protein-bound functionalized xenon. An increase in the functionalized-xenon resonance linewidth is apparent in the spectrum upon binding to the protein. The exchange rates of both protein-bound and free functionalized xenon were measured to investigate the origin of broadening in the protein-bound functionalized-xenon resonance. Finally, two methods for signal-to-noise amplification by selective excitation of bound xenon are also presented. Implications of these studies for the application of the functionalized-xenon biosensors in the ordinary and multiplexing capacity are discussed.

\section{Materials and Methods}

\section{NMR experiments}

All ${ }^{129} \mathrm{Xe}$ NMR spectra shown were obtained at $83 \mathrm{MHz}\left({ }^{1} \mathrm{H}=300 \mathrm{MHz}\right)$ on a Varian Inova spectrometer. When selective excitation experiments were performed, frequency-selective EBURP1 and IBURP2 pulses $^{54}$ were generated using the PBox program (Varian Instruments). Both selective pulses are designed to excite a bandwidth of $1.8 \mathrm{kHz}$ centered at $10.25 \mathrm{kHz}$ upfield of the frequency of xenon in water, corresponding to a $\sim 21.8 \mathrm{ppm}$ excitation window centered about the NMR frequency of xenon bound to water-soluble cryptophanes. Natural-abundance xenon (Isotec or Spectra Gases) was laser-polarized using a commercial polarizer (Amersham Health, Durham, NC) and introduced to the sample using previously described methods, ${ }^{42}$ with polarizations of $1-5 \%$. In order to remove molecular oxygen, samples were degassed via several freeze-pump-thaw cycles prior to the introduction of xenon. Experiments involving water-soluble cryptophanes were carried out at $298 \mathrm{~K}$ in $\mathrm{D}_{2} \mathrm{O}$. The spectrum of xenon in allyl-functionalized cryptophane (16) was obtained at $213 \mathrm{~K}$ in a $25 \%$ toluene/75\% tetrachloroethane solvent mixture. All chemical shifts were referenced by assigning the xenon in $\mathrm{D}_{2} \mathrm{O}$ resonance to $195 \mathrm{ppm}$ except for spectra of Figure 3a and Figures 4b-4e. The spectrum of Figure 3a was referenced to the shift of xenon gas when extrapolated to 0 atm pressure. The spectra of Figures 4b-4e were referenced to the spectrum of Figure 4a. Acquisition time was 1s with a spectral width of 60 $\mathrm{kHz}$ except for exchange-rate measurement data which necessitated shorter acquisitions as dictated by 
the mixing time. Fourier transformed spectra were processed with zero filling and Gaussian linebroadening values of $2 \mathrm{~Hz}$ in Figures $3 \mathrm{~b}$ and 3c; $<10 \mathrm{~Hz}$ in Figure 5; $10 \mathrm{~Hz}$ in Figures 4, 7, 8; and 20 $\mathrm{Hz}$ for intensities integrated in Figure 6. Ninety-degree pulses were used for acquiring spectra unless otherwise noted. Exchange signal-averaging was used for the spectra shown in Figures 4c through 4e (n $=10)$ and also for Figure $6(n \geq 3)$. Specific pulse sequences for exchange measurement and exchange signal-averaging techniques are presented in the corresponding figures. For both the exchange signalaveraging and indirect-assay experiments, $\tau_{\operatorname{mix}}$ was at least $150 \mathrm{~ms}$. Concentrations of particular biosensor samples are noted where relevant and were determined before addition of protein by UV-VIS spectrophotometry using a molar absorptivity for water-soluble cryptophanes $\left(\varepsilon_{287}=8000 \mathrm{M}^{-1}\right)$, as determined by the dry weight method. The molar absorptivity for cryptophane in aqueous solution was found to be different than that previously used for cryptophane in organic solution. ${ }^{51}$

\section{Synthetic Strategy}

Preparation of the cryptophane-acetic acid cage (1, Figure 2), which is the precursor to the biosensor 

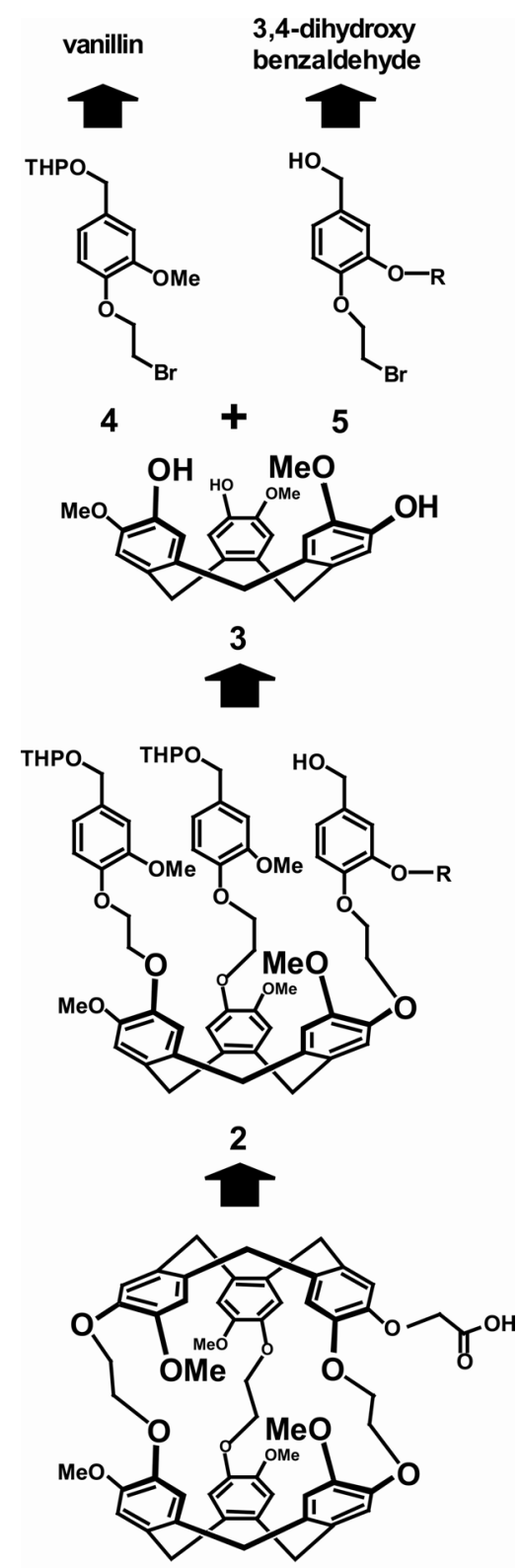

1

Figure 2. Retrosynthesis of derivatized cryptophane.

molecule, was based on the template method previously reported by Collet and co-workers. ${ }^{55}$ A key feature in the preparation of such derivatized cryptophanes is the substitution of one of the methyl ether groups for a suitable reactive moiety such as 2-acetic acid. As shown in Figure 2, we envisioned this substitution in the final product to originate from the derivatization of a 3,4-dihydroxybenzaldehyde precursor at the meta position. Our initial effort with $\mathrm{R}=$ methyl 2-acetate was unproductive due to side reactions in the final cyclization step. We thus opted to substitute this position with a protecting group, 
and mindful of the stereoelectronic impact of protecting groups on the cyclization efficiency ${ }^{55}$ we selected an allyl group. This protecting group is indeed known to give good cyclization yield, ${ }^{55,56}$ and the direct elaboration of the allyl functionality via oxidation offers alternatives to a deprotectionalkylation sequence. We thus needed access to $\mathbf{5}$ where $\mathrm{R}$ is an allyl group. Selective meta-allylation of 3,4-dihydroxybenzaldehyde has been reported using 2 equivalents of sodium hydride to generate the bisphenoxide anion prior to allyl bromide addition. ${ }^{57}$ It is important to note that the monodeprotonated 3,4-dihydroxybenzaldehyde exhibits excellent selectivity for para-alkylation by virtue of the lower acidity of the conjugate para-phenol. Incomplete deprotonation leads to compromised selectivity. Scheme 1 shows a practical alternative for the preparation of 3-allyloxy-4-hydroxy benzaldehyde (7) that

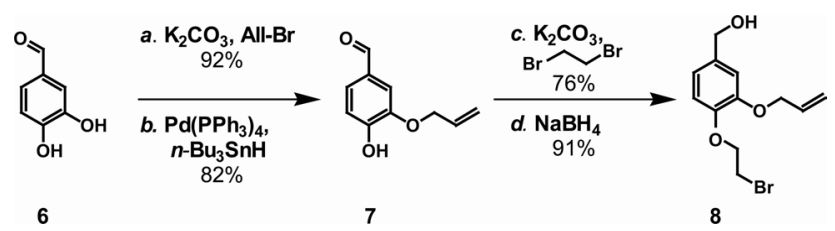

Scheme 1. $a . \mathrm{K}_{2} \mathrm{CO}_{3}$ (2.5 equiv), All-Br (2.2 equiv), DMF, $80{ }^{\circ} \mathrm{C}, 2 \mathrm{~h}, 92 \% ; b . \mathrm{Pd}\left(\mathrm{PPh}_{3}\right)_{4}(2.5 \mathrm{~mol} \%), n$ $\mathrm{Bu}_{3} \mathrm{SnH}$ (1.25 equiv), $\mathrm{CH}_{2} \mathrm{Cl}_{2}, 23{ }^{\circ} \mathrm{C}, 1.5 \mathrm{~h}, 82 \% ; c . \mathrm{K}_{2} \mathrm{CO}_{3}$ (1.2 equiv), 1,2-dibromoethane (4.0 equiv), DMF, $80{ }^{\circ} \mathrm{C}, 8$ h, 76\%; $d . \mathrm{NaBH}_{4}\left(1.0\right.$ equiv), $\mathrm{MeOH}$ (10 equiv), THF, $0{ }^{\circ} \mathrm{C}, 0.5 \mathrm{~h}, 91 \%$.

involves first the allylation of both hydroxyl groups of the 3,4-dihydroxybenzaldehyde (6) followed by the selective deprotection at the para position by palladium mediated allyl-transfer. It is speculated that the selectivity in the deprotection stems from the kinetically favored $\pi$-allyl insertion into the more acidic phenolic position. Subsequent para derivatization with 1,2-dibromoethane and reduction were carried out according to previously reported procedures to obtain $\mathbf{8}$ in good yield. ${ }^{56}$

Our next task was to selectively introduce either 2 units of 4 or 1 unit of 8 onto the cyclotriveratrylene template. As shown in Scheme 2, we opted to deprotect the now tris allyl protected cyclotriveratrylene 


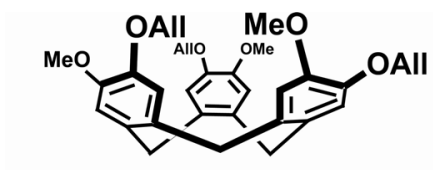

9

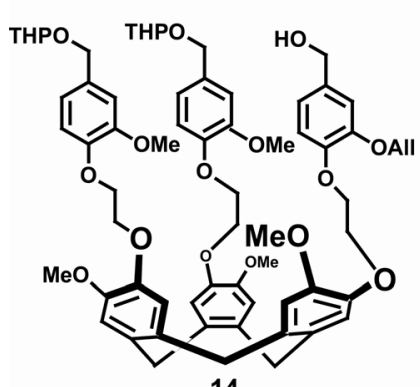

$55-60 \% \downarrow f . \mathrm{HCO}_{2} \mathrm{H}$

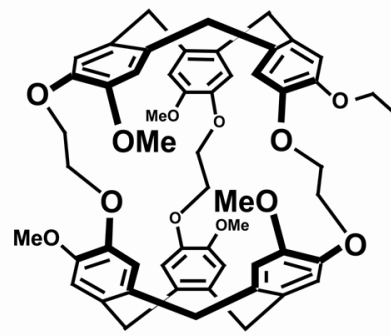

15
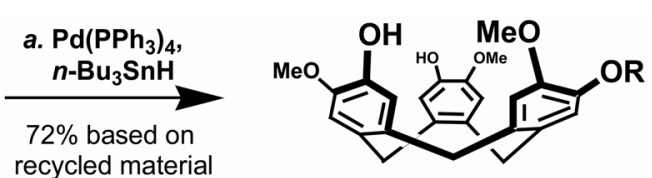

$$
\text { b. } \mathrm{Cs}_{2} \mathrm{CO}_{3}, \mathrm{All}-\mathrm{Br} \longrightarrow \begin{array}{r}
\text { 10: } \mathrm{R}=\mathrm{All} \\
\text { 3: } \mathrm{R}=\mathrm{H}
\end{array}
$$

c. $4, \mathrm{~K}_{2} \mathrm{CO}_{3}, n-\mathrm{Bu}_{4} \mathrm{NI} \downarrow 81 \%$
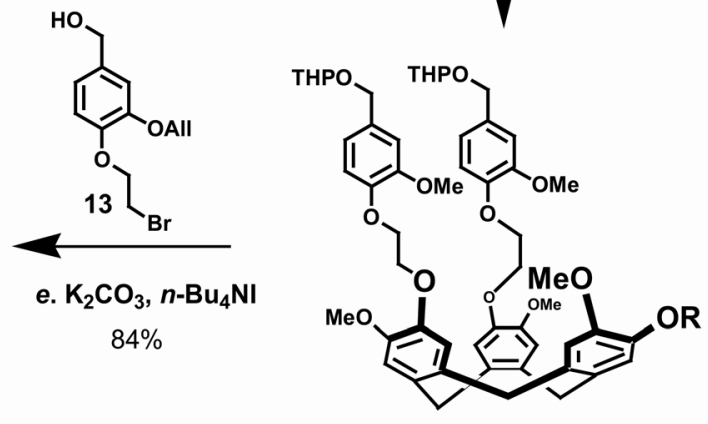

d. $\mathrm{Pd}\left(\mathrm{PPh}_{3}\right)_{4}, n-\mathrm{Bu}_{3} \mathrm{SnH} \longrightarrow$ 11: $\mathrm{R}=\mathrm{All}$ $89 \%$

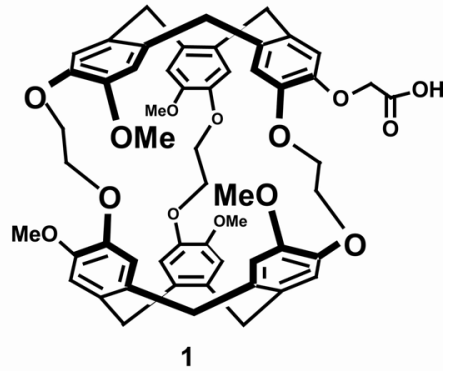

Scheme 2. Synthesis of derivatized cryptophanes 16. a. $\mathrm{Pd}\left(\mathrm{PPh}_{3}\right)_{4}(10 \mathrm{~mol} \%), n-\mathrm{Bu}_{3} \mathrm{SnH}(2.0$ equiv), $\mathrm{CH}_{2} \mathrm{Cl}_{2}, 23{ }^{\circ} \mathrm{C}, 1.5 \mathrm{~h}, 72 \%$ of $\mathbf{1 0}$ based on recycled material; $b . \mathrm{Cs}_{2} \mathrm{CO}_{3}$ (1.0 equiv), All-Br (1.0 equiv), DMF, $80^{\circ} \mathrm{C}, 2 \mathrm{hr}, 67 \%$ based on recycled material; c. 4 (2.5 equiv), $\mathrm{K}_{2} \mathrm{CO}_{3}$ (2.5 equiv), $n$-Bu $\mathrm{NI}_{4}(0.1$ equiv), DMF, $80{ }^{\circ} \mathrm{C}, 8 \mathrm{~h}, 81 \%$; d. $\mathrm{Pd}\left(\mathrm{PPh}_{3}\right)_{4}(10 \mathrm{~mol} \%), n-\mathrm{Bu}_{3} \mathrm{SnH}$ (1.5 equiv), $\mathrm{CH}_{2} \mathrm{Cl}_{2}, 23{ }^{\circ} \mathrm{C}, 1.5 \mathrm{~h}$, $89 \% ;$ e. 13 (1.2 equiv), $\mathrm{K}_{2} \mathrm{CO}_{3}$ (1.5 equiv), $n$-Bu $\mathrm{NI}$ (0.1 equiv), $\mathrm{DMF}, 80{ }^{\circ} \mathrm{C}, 8 \mathrm{~h}, 84 \% ; f .14$ at $1 \mathrm{mM}$ in $\mathrm{HCO}_{2} \mathrm{H}, 55^{\circ} \mathrm{C}, 3.5 \mathrm{~h}, 55-60 \% ; g . \mathrm{Pd}\left(\mathrm{PPh}_{3}\right)_{4}(10 \mathrm{~mol} \%), n-\mathrm{Bu}_{3} \mathrm{SnH}$ (2.0 equiv), $\mathrm{CH}_{2} \mathrm{Cl}_{2}, 23{ }^{\circ} \mathrm{C}, 1.5 \mathrm{~h}$; h. $\mathrm{Cs}_{2} \mathrm{CO}_{3}$ (1.5 equiv), methyl bromoacetate (1.5 equiv), DMF, $50{ }^{\circ} \mathrm{C} ; i$. LiOH (2.0 equiv), THF:MeOH (3:1), $23{ }^{\circ} \mathrm{C}, 1 \mathrm{~h}, 74 \%$ from 15. 
with substoichiometric amounts of reagents to obtain the desired monoprotected $\mathbf{1 0}$ as well as the bisprotected and fully deprotected material. The undesired materials were recycled by resubjection to the deprotection conditions or reintroduction of an allyl group. Two units of $\mathbf{4}$ were then introduced under standard alkylation conditions to afford 11. The remaining allyl protecting group on cyclotriveratrylene template 11 was removed to afford phenol 12, which was alkylated with 13 to afford the cyclization precursor 14. The templated cyclization of $\mathbf{1 4}$ proceeded smoothly according to the previously reported conditions ${ }^{55}$ to provide cryptophane 15 in 55-60\% yield. Direct conversion of the allyl group to the carboxylic acid using catalytic amounts of $\mathrm{RuCl}_{3}$ and $\mathrm{NaIO}_{4}$ afforded a complex mixture of products. Instead, the desired 2-cryptophaneacetic acid 1 was obtained by the removal of the allyl group and the resulting phenol was alkylated with methyl 2-bromoacetate followed by $\mathrm{LiOH}$ saponification.

A highly charged 3-amino-acid peptide (16, Scheme 3) was attached to (1) at the acetic acid site, to

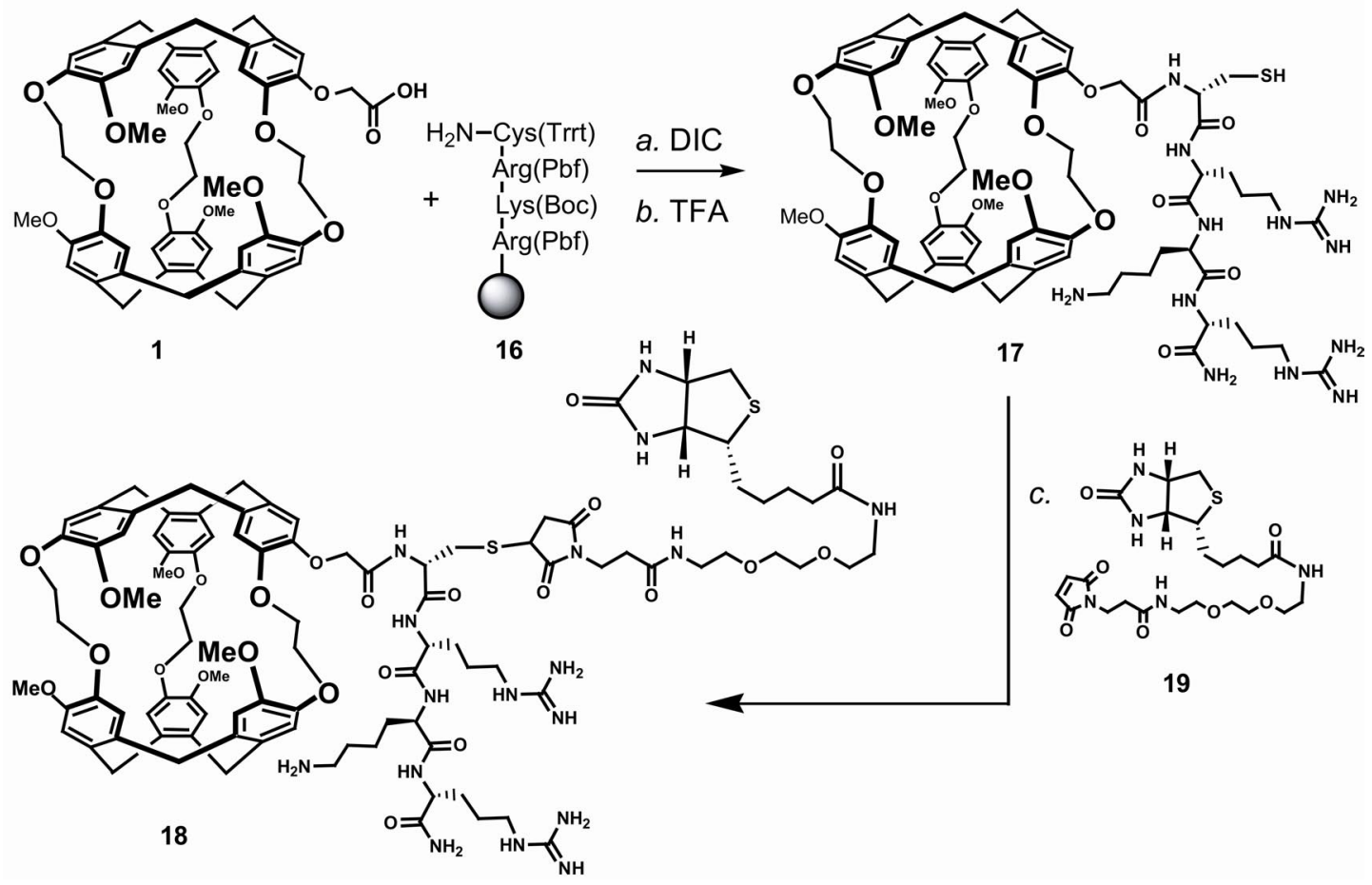


Scheme 3. Synthesis of biotin derivatized cryptophane. a. 1 (0.8 equiv), DIC (2.0 equiv), 4-DMAP (0.5 equiv), DMF, $23{ }^{\circ} \mathrm{C}, 6 \mathrm{~h} ; \mathrm{Ac}_{2} \mathrm{O}\left(5.0\right.$ equiv), $23{ }^{\circ} \mathrm{C}, 2 \mathrm{~h} ; b$. TFA:m-cresol 4:1, $23{ }^{\circ} \mathrm{C}, 2.5 \mathrm{~h}, 51 \% ; c .19$ (2.0 equiv), $\mathrm{H}_{2} \mathrm{O}, \mathrm{pH} 7,23^{\circ} \mathrm{C}, 2 \mathrm{~h}, 62 \%$

allow for solubility of the biosensor in water. The peptide was prepared as a polymer-bound unit using standard Fmoc chemistry with DIC/HOBt couplings on a Rink amide resin where it was capped with 2cryptophaneacetic acid (1) using a DIC mediated coupling catalyzed with 4-DMAP. The cryptophane moiety adds significant lypophilicity to the compound and makes the cryptophane-capped peptide readily separable from the uncapped peptide; therefore, a substoichiometric amount of the precious cage precursor (1) was used to assure the complete consumption of the cage. After the coupling, the compound was released from the resin, with concomitant side-chain deprotection, to obtain the cryptophane-peptide adduct 17 . The thiol of the cysteine residue was selectively derivatized with biotin-maleamide conjugate 19 under standard conditions to obtain the desired biotinylated cryptophane adduct 18 .

\section{Synthetic details}

The 3,4-dihydroxybenzaldehyde 6 (5.00 g, $36.2 \mathrm{mmol}, 1.0$ equiv) was dissolved in anhydrous DMF at room temperature and treated with $\mathrm{K}_{2} \mathrm{CO}_{3}(12.5 \mathrm{~g}, 90.6 \mathrm{mmol}, 2.5$ equiv). Allyl bromide $(9.63 \mathrm{~g}, 79.7$ mmol, 2.2 equiv) was then added and the reaction was warmed to $80^{\circ} \mathrm{C}$. After 2 hours, TLC analysis revealed complete conversion of the starting material to the desired bisallylated product. The reaction mixture was poured into a 1:1 mixture of $\mathrm{Et}_{2} \mathrm{O}: \mathrm{EtOAc}(150 \mathrm{~mL})$, washed with $1 \mathrm{M} \mathrm{HCl}(2 \times 100 \mathrm{~mL})$ and brine $(100 \mathrm{~mL})$. The organic layer was dried over $\mathrm{MgSO}_{4}$ and concentrated in vacuo. The crude oil was purified by flash chromatography on silica gel using a $10 \%$ to $40 \%$ gradient of EtOAc in hexane to recover $7.27 \mathrm{~g}$ of colorless oil which slowly crystallized over several days ( $92 \%$ yield).

The 3,4-diallyoxybenzaldehyde (7.27 g, $33.3 \mathrm{mmol}, 1.0$ equiv) was dissolved in $\mathrm{CH}_{2} \mathrm{Cl}_{2}(100 \mathrm{~mL})$ and treated with $\mathrm{Pd}\left(\mathrm{PPh}_{3}\right)_{4}(0.985 \mathrm{~g}, 0.833 \mathrm{mmol}, 0.025$ equiv $)$ at room temperature followed by drop-wise 
addition of $n-\mathrm{Bu}_{3} \mathrm{SnH}(9.60 \mathrm{~g}, 33.3 \mathrm{mmol}, 1.0$ equiv). The reaction was allowed to proceed for $30 \mathrm{~min}$ after which TLC analysis indicated ca. $20 \%$ remaining starting material. Additional $n$ - $\mathrm{Bu}_{3} \mathrm{SnH}(3.84 \mathrm{~g}$, $8.32 \mathrm{mmol}, 0.25$ equiv) was added to drive the reaction to completion. The reaction mixture was concentrated in vacuo and purified by flash chromatography on silica gel, eluting first with 10\% EtOAc in hexane, followed by a gradient from $20 \%$ to $50 \%$ of EtOAc in hexane to recover $4.34 \mathrm{~g}$ of 7 as colorless oil which slowly crystallized over time ( $82 \%$ yield).

Mono-protected phenol 7 (4.34 g, $24.6 \mathrm{mmol}, 1.0$ equiv) in DMF (50 mL) at $80{ }^{\circ} \mathrm{C}$ was treated with $\mathrm{K}_{2} \mathrm{CO}_{3}$ (4.10 g, $29.5 \mathrm{mmol}, 1.2$ equiv) followed by 1,2-dibromoethane (18.4 g, $98.4 \mathrm{mmol}, 4.0$ equiv). The reaction was allowed to proceed for $8 \mathrm{~h}$ after which it was diluted with $\mathrm{Et}_{2} \mathrm{O}(300 \mathrm{~mL})$ and washed with $1 \mathrm{M} \mathrm{HCl}(3 \times 100 \mathrm{~mL})$. The organic phase was dried over $\mathrm{MgSO}_{4}$, concentrated in vacuo and purified by flash chromatography on silica gel, eluting with a gradient from $20 \%$ to $50 \%$ of EtOAc in hexane to recover $5.37 \mathrm{~g}$ (76\% yield). This material $(18.7 \mathrm{mmol})$ was dissolved in THF $(50 \mathrm{~mL})$, cooled to $0{ }^{\circ} \mathrm{C}$ and reacted with $\mathrm{NaBH}_{4}(1.09 \mathrm{~g}, 18.7 \mathrm{mmol}, 1.0$ equiv) followed by $\mathrm{MeOH}(4.7 \mathrm{~mL}, 187 \mathrm{mmol}$, 10 equiv). The reaction was stirred for $30 \mathrm{~min}$ at $0{ }^{\circ} \mathrm{C}$ then poured over $1 \mathrm{M} \mathrm{HCl}(100 \mathrm{~mL})$ and extracted with $\mathrm{CH}_{2} \mathrm{Cl}_{2}(3 \times 100 \mathrm{~mL})$. The combined organic phases were dried over $\mathrm{MgSO}_{4}$, concentrated in vacuo and purified by flash chromatography on silica gel, eluting with 50\% EtOAc in hexane to recover $4.92 \mathrm{~g}$ of alcohol 8 (91\% yield).

The allyl protected cyclotriveratrylene 9 (2.82 g, $5.33 \mathrm{mmol}, 1.0$ equiv) in $\mathrm{CH}_{2} \mathrm{Cl}_{2}(20 \mathrm{~mL})$ at $23{ }^{\circ} \mathrm{C}$ was treated with $\mathrm{Pd}\left(\mathrm{PPh}_{3}\right)_{4}(0.615 \mathrm{~g}, 0.533 \mathrm{mmol}, 0.1$ equiv) and followed by a slow addition of tributyltin hydride $(3.10 \mathrm{~g}, 10.66 \mathrm{mmol}, 2.0$ equiv). After $2 \mathrm{hrs}$, the reaction was concentrated and loaded directly onto a silica gel column. An elution of $1: 1 \mathrm{CH}_{2} \mathrm{Cl}_{2}$ : hexanes was used until all the tin byproducts were removed, followed by a gradient from 0 to $40 \%$ of $\mathrm{Et}_{2} \mathrm{O}$ in $\mathrm{CH}_{2} \mathrm{Cl}_{2}$ in order to recover $0.668 \mathrm{~g}$ of desired monoprotected cyclotriveratrylene $10(28 \%)$, as well as byproducts bisprotected cyclotriveratrylene $(34 \%, 0.887 \mathrm{~g})$ and fully deprotected cyclotriveratrylene $(26 \%, 565 \mathrm{mg})$. The undesired compounds could be recycled by allylation in a mixture of allyl bromide (5.0 equiv) and cesium carbonate (5.0 equiv) in $\mathrm{DMF}$ at $80^{\circ} \mathrm{C}$ for $3 \mathrm{~h}$. 
The mono protected cyclotriveratrylene 10 (700 mg, $1.56 \mathrm{mmol}, 1.0$ equiv) was dissolved in DMF (10 $\mathrm{mL}$ ) and treated with $\mathrm{K}_{2} \mathrm{CO}_{3}(540 \mathrm{mg}, 3.89 \mathrm{mmol}, 2.5$ equiv) followed by the addition of bromide 4 (1.34 g 3.89 mmol, 2.5 equiv) and tetrabutylamonium iodide (60 mg, $0.156 \mathrm{~g}, 0.1$ equiv). The reaction was stirred for $8 \mathrm{~h}$ at $80^{\circ} \mathrm{C}$ after which it was diluted with EtOAc $(100 \mathrm{~mL})$ and washed with brine $(3 \mathrm{x}$ $100 \mathrm{~mL})$. The crude product was purified by flash chromatography (50\% EtOAc in hexanes) to recover $1.22 \mathrm{~g}$ of compound $\mathbf{1 1}$.

Compound 11 (1.1 g, $1.12 \mathrm{mmol}, 1.0$ equiv) was dissolved in $\mathrm{CH}_{2} \mathrm{Cl}_{2}(5 \mathrm{~mL})$ at $23{ }^{\circ} \mathrm{C}$, and $\mathrm{Pd}_{(}\left(\mathrm{PPh}_{3}\right)_{4}$ ( $0.129 \mathrm{~g}, 0.112 \mathrm{mmol}, 0.1$ equiv) was added followed by tributyltin hydride $(0.492 \mathrm{~g}, 1.68 \mathrm{mmol}, 1.5$ equiv). After $3 \mathrm{hrs}$, the reaction was concentrated onto silica and loaded directly onto a short column. An elution of 1:9 EtOAc:hexanes was used until all the tin byproducts were removed, then with 3:1 EtOAc:hexanes elution was used to recover $0.934 \mathrm{~g}$ of phenol 12.

Phenol 12 (480 mg, $0.512 \mathrm{mmol}, 1.0$ equiv) in DMF (10 mL) was treated with $\mathrm{K}_{2} \mathrm{CO}_{3}(107 \mathrm{mg}, 0.768$ mmol, 1.5 equiv) followed by bromide 8 ( $0.173 \mathrm{~g} 0.614 \mathrm{mmol}, 1.2$ equiv) and tetrabutylamonium iodide. The reaction was stirred for $8 \mathrm{~h}$ at $80^{\circ} \mathrm{C}$ after which it was diluted with EtOAc $(100 \mathrm{~mL})$ and washed with brine $(3 \times 100 \mathrm{~mL})$. The crude product was purified by flash chromatography $(50 \%$ EtOAc in hexanes) to recover $0.491 \mathrm{~g}$ of compound $\mathbf{1 4}$.

Compound 14 (400 mg, $0.350 \mathrm{mmol})$ was dissolved in chloroform $(6 \mathrm{~mL})$ and formic acid $(500 \mathrm{~mL})$ was added. The reaction was heated to $55^{\circ} \mathrm{C}$ for $2.5 \mathrm{hr}$, concentrated and chromatographed using a gradient from 0 to $15 \%$ of acetone in $\mathrm{CH}_{2} \mathrm{Cl}_{2}$ to recover $187 \mathrm{mg}$ of pure cryptophane 15 .

Cryptophane 15 (208 mg, $0.226 \mathrm{mmol}, 1.0$ equiv) in $\mathrm{CH}_{2} \mathrm{Cl}_{2}(5 \mathrm{~mL})$ at $23{ }^{\circ} \mathrm{C}$ was treated with $\mathrm{Pd}\left(\mathrm{PPh}_{3}\right)_{4}(26 \mathrm{mg}, 0.026 \mathrm{mmol}, 0.1$ equiv) and followed by the addition of tributyltin hydride (132 mg, 0.452 mmol, 2.0 equiv). After $1.5 \mathrm{hrs}$, the reaction was concentrated, redissolved in DMF and $\mathrm{Cs}_{2} \mathrm{CO}_{3}$ (101 mg, 0.312, 1.5 equiv) was added, followed by the addition of methyl bromoacetate (48 $\mathrm{mg}, 0.312$ mmol, 1.5 equiv). The reaction was stirred at $50{ }^{\circ} \mathrm{C}$ for $3 \mathrm{~h}$ then diluted with EtOAc $(50 \mathrm{~mL})$ and finally washed with brine $(3 \times 30 \mathrm{~mL})$. The crude material was redissolved in THF $(6 \mathrm{~mL})$ and treated with a solution of $\mathrm{LiOH}\left(10.4 \mathrm{mg}, 0.452 \mathrm{mmol}, 2.0\right.$ equiv) dissolved in $\mathrm{H}_{2} \mathrm{O}$. The reaction was stirred at $23{ }^{\circ} \mathrm{C}$ 
for $1 \mathrm{~h}$ then acidified with $1 \mathrm{M} \mathrm{HCl}(10 \mathrm{~mL})$ and extracted with $\mathrm{CH}_{2} \mathrm{Cl}_{2}(3 \times 50 \mathrm{~mL})$. The combined organic layers were dried over $\mathrm{MgSO}_{4}$ and concentrated in vacuo. The crude product was purified by flash chromatography on silica gel using a gradient from 0 to $10 \%$ of $\mathrm{MeOH}$ in $\mathrm{CH}_{2} \mathrm{Cl}_{2}$ to recover 157 mg of cryptophane $\mathbf{1}$ as a white solid.

The dissolution of cryptophane 1 (52 $\mathrm{mg}, 55.4 \mu \mathrm{mol}, 0.8$ equiv) in DMF ( $2 \mathrm{~mL})$ was followed by the addition of resin 16 (140 mg, $70 \mu \mathrm{mol}, 1.0$ equiv, prepared by standard Fmoc chemistry on a Rink linker), then DIC (16.8 mg, $110.8 \mu \mathrm{mol}, 2.0$ equiv) and finally 4-DMAP (13.3 mg, $110.4 \mu \mathrm{mol}, 0.8$ equiv). The reaction was shaken for $6 \mathrm{hr}$ after which TLC analysis of the supernatant revealed complete consumption of cryptophane 1. The resin was filtered and washed with $\mathrm{DMF}$ and $\mathrm{CH}_{2} \mathrm{Cl}_{2}$, then treated with $2 \mathrm{~mL}$ of a 4:1 solution of TFA: $m$ cresol for $2.5 \mathrm{~h}$. The cleavage solution was added dropwise to $\mathrm{Et}_{2} \mathrm{O}(50 \mathrm{~mL})$ and the precipitates were pelleted by centrifugation $(9000 \mathrm{~g})$. The pellet was redisolved in a 1:1 solution of $\mathrm{AcCN}: \mathrm{H}_{2} \mathrm{O}$ and purified by HPLC using a semi-preparative column (5 to $100 \%$ AcCN in water with $0.1 \%$ TFA over $40 \mathrm{~min}$ with a $20 \mathrm{~mL} / \mathrm{min}$ flow). The product was collected at 20$22 \mathrm{~min}$, and it was frozen then lyophilized to recover $43 \mathrm{mg}$ of pure cryptophane adduct 17 as a TFA salt.

The aqueous $\left(0.2 \mathrm{~mL} \mathrm{H} \mathrm{H}_{2} \mathrm{O}\right)$ solution of cryptophane adduct 17 (10 $\mathrm{mg}, 5.3 \mu \mathrm{mol}, 1.0$ equiv) was combined with a solution of biotin $19\left(3.0 \mathrm{mg}, 10.6 \mu \mathrm{mol}, 2.0\right.$ equiv) in $\mathrm{H}_{2} \mathrm{O}(0.2 \mathrm{~mL})$. The $\mathrm{pH}$ of the reaction was adjusted to 7 with a $10 \% \mathrm{~K}_{2} \mathrm{CO}_{3}$ solution. After $2 \mathrm{hr}$, the crude mixture was loaded on a semi-preparative HPLC column (5 to $100 \% \mathrm{AcCN}$ in water with $0.1 \%$ TFA over 40 min with a 20 $\mathrm{mL} / \mathrm{min}$ flow) and the product collected was at 24-25 min. After freezing, the fraction was lyophilized to recover $7.2 \mathrm{mg}$ of pure cryptophane adduct $\mathbf{1 8}$ as a TFA salt.

\section{Results and Discussion}

\section{Biosensor Molecule Diastereomers Detected by Functionalized Xenon}

The spectrum of xenon in a solution of the biotin-derivatized cryptophane (Figure 1), in the absence of protein, contains four peaks near $\sim 70 \mathrm{ppm}$ (Figure 3c) from xenon inside the cryptophane(s) and a 

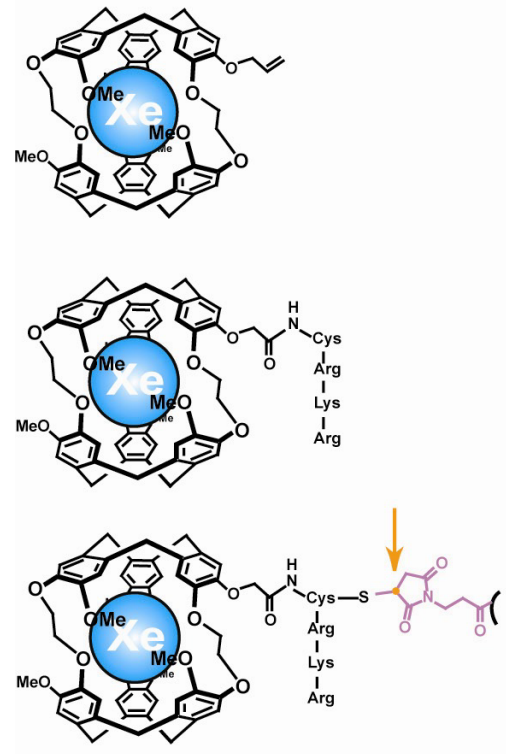
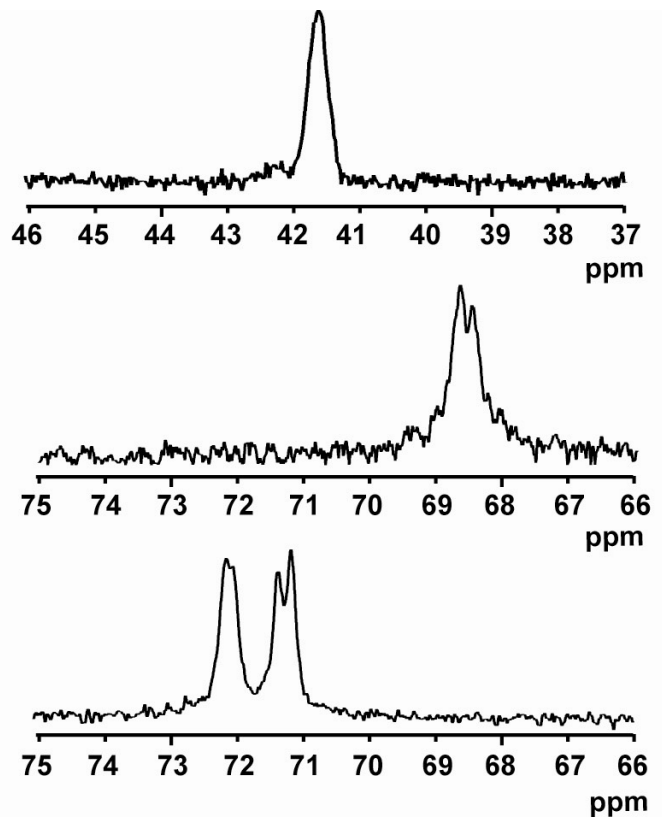

(B)

(A)

(C)

Figure 3. Detection of cage diastereomers by xenon chemical shift. The laser-polarized xenon spectrum of allyl-substituted cryptophane-A in $25 \%$ toluene $/ 75 \%$ tetrachloroethane shows only one peak, with a line-width of $0.2 \mathrm{ppm}$ (A). The addition of a single-enantiomer peptide chain to the cage leads to two xenon resonances $(\mathrm{B})$, separated by $\sim 0.10 \mathrm{ppm}$. The xenon spectrum after the addition of a biotin linker shows four lines $(\mathrm{C})$, reflecting the effect of a racemic mixture at a chiral carbon seven bonds away from the cage itself.

peak at $\sim 195 \mathrm{ppm}$ that corresponds to xenon dissolved in water (not shown). We attribute the four functionalized-xenon peaks to distinct xenon chemical shifts arising from the diastereomers of the biosensor molecule.

Cryptophane-A is chiral, ${ }^{55}$ and xenon dissolved in a racemic mixture of the cage enantiomers gives rise to a single resonance. ${ }^{31}$ Similarly, the xenon spectrum for a racemic mixture of the allyl-substituted cryptophane-A cage enantiomers (15) shows only one resonance (Figure 3a). However, the spectra of the xenon biosensor exhibit multiple peaks rather than a single resonance (Figure $3 \mathrm{c}$ ). This is a consequence of the formation of diastereomer biosensor molecules resulting from the addition of new 
chiral centers to the cage precursor (15). The first pair of diastereoisomers is formed by the introduction of chiral L-amino acids Cys, Lys and Arg. The corresponding xenon spectrum (Figure $3 b$ ) of this mixture has two lines separated by $0.15 \mathrm{ppm}$, attributed to the RL and LL cage-peptide coupled biosensor intermediates. When linking the peptide-derivatized cage to the biotin linker, a new racemic chiral center is formed at the connection involving the Cys residue and the prochiral maleimide (marked with an arrow in Figure 3c). As a result, the product is now a mixture of chiral combinations RLR, RLL, LLR, LLL; correspondingly, the spectrum of xenon in the conjugate(s) contains four distinct peaks. The fact that the biotin ligand itself is chiral does not affect the number of peaks predicted

The direct correlation between the number of observed peaks and the number of diastereomers is apparent from Figures $3 \mathrm{~b}$ and $3 \mathrm{c}$. The identity of diastereomers has not yet been directly verified, and further experimental studies are needed to better characterize the connection between the chirality of biosensor molecule components and the xenon chemical shift. Recently, theoretical studies have begun to probe the chiral nature of the interaction between the xenon chemical shift and the cryptophane-A cage, ${ }^{58,59}$ and model helices have been used to investigate the interaction of xenon with diastereomers. 60-63

Previous experimental studies, which are now being understood with theoretical models by Sears and Jameson, ${ }^{64}$ have shown that direct changes to the basic structure of the cryptophane-A cage perturb the chemical shift of the cryptophane-encapsulated xenon. For example, a $30 \mathrm{ppm}$ change in chemical shift was noted when the length of the bridges between the cyclotriveratrylene caps of cryptophane-A was increased by one methylene group, ${ }^{51}$ and even deuteration of a single methoxy group on a cryptophaneA cage has been shown to produce a noticeable shift $(\sim 0.1 \mathrm{ppm}){ }^{65}$ In this work, we show that significant xenon chemical shift differences also result from derivatizations of cryptophane-A that are not local to the encapsulated xenon. Namely, the presence of chiral centers attached to the outside of the cage cause changes of up to $\sim 1 \mathrm{ppm}$ in the xenon chemical shift. The sensitivity of xenon to indirect changes in cage structure or environment is important for distinguishing bound and free ligand in addition to offering greater potential for multiplexing the xenon biosensor. By combining different 
chemical changes in and around the cryptophane it will be possible to tune the chemical shift of the xenon in the cage, making it possible to follow binding events of different ligand-cage combinations in parallel. $^{51}$

\section{Characteristics of Protein-Bound Functionalized Xenon Spectrum}

\section{Titration of Biotinylated Functionalized-Xenon Biosensor with Avidin Protein}

We previously showed that the chemical shift of the biotinylated cryptophane-A biosensor is sensitive to the presence of avidin. ${ }^{51}$ We have now extended the experiments to a complete titration of the free biosensor with avidin (Figure 4) showing that increasing amounts of avidin lead to corresponding
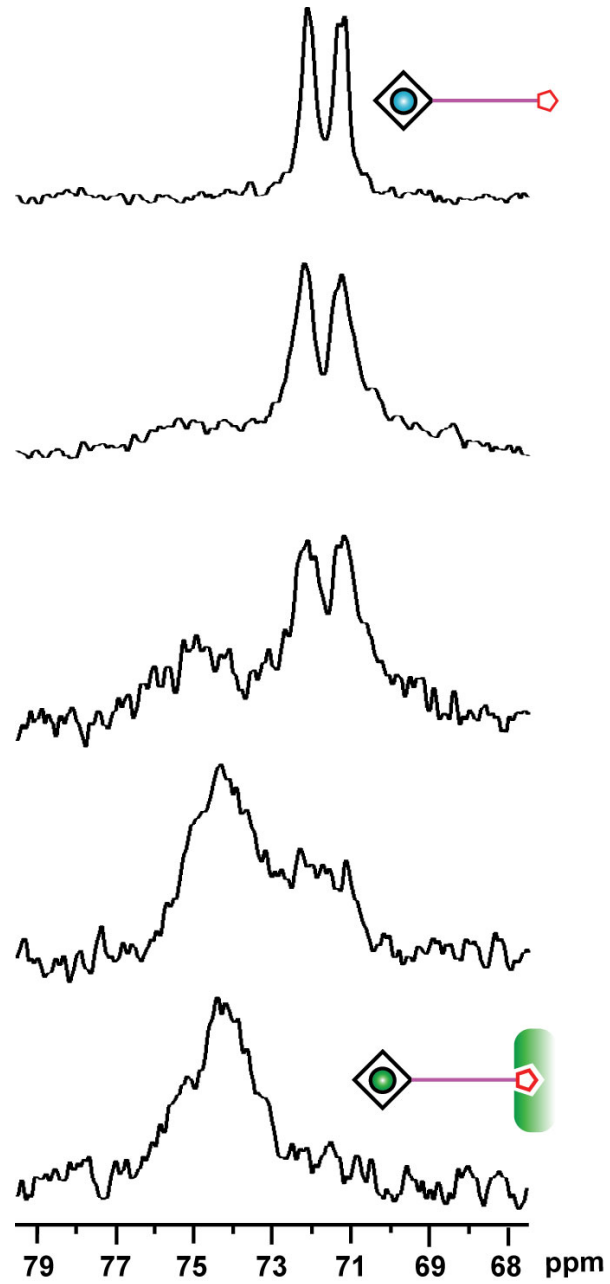

(A)

(B)

(C)

(D)

(E) 
Figure 4. Detection of biotin-avidin binding with xenon NMR. The ${ }^{129} \mathrm{Xe}$ NMR spectra of the functionalized xenon biosensor at various titration points, namely: A. $0 \%(300 \mu \mathrm{M}$ biosensor, $0 \mu \mathrm{M}$ avidin); B. $10 \%(1800 \mu \mathrm{M}, 170 \mu \mathrm{M})$; C. $20 \%(1800 \mu \mathrm{M}, 350 \mu \mathrm{M})$; D. $60 \%(300 \mu \mathrm{M}$ with $180 \mu \mathrm{M})$; and E. $120 \%(300 \mu \mathrm{M}, 360 \mu \mathrm{M})$. These spectra show a new resonance and marked broadening in response to the increasing amounts of avidin. Spectra in C, D, and E were exchange signal averaged as described in the NMR experimental section.

changes in the xenon spectrum. Biosensor-avidin solutions used for Figures 4a to 4e, have amounts of avidin monomer that are $0 \%, 10 \%, 20 \%, 60 \%$, and $120 \%$ of total biosensor concentration, respectively (see figure caption for concentration values). The addition of avidin to free biosensor leads to the appearance of a broad, downfield resonance accompanied by a decrease in the intensity of the free biosensor resonances (Figure 4b). The spectral changes continue in this manner with increasing amounts of avidin (Figures $4 \mathrm{c}$ and $4 \mathrm{~d}$ ). The addition of a full equivalent of avidin results in a single peak about 3 ppm downfield (Figure 4e). The appearance of a single, broadened peak for protein-bound biosensor indicates that functionalized xenon resonances undergo a significant increase in linewidth when compared to those of the free biosensor.

\section{Verification of Correspondence between Spectral Changes and Binding Event}

When the biotinylated xenon biosensor $(300 \mu \mathrm{M})$ is added to avidin $(180 \mu \mathrm{M})$ that had been preequilibrated with a five-fold excess of normal biotin, the xenon spectrum is unchanged compared to that of the same concentration of biosensor alone (Figure 5). This control experiment demonstrates that the 

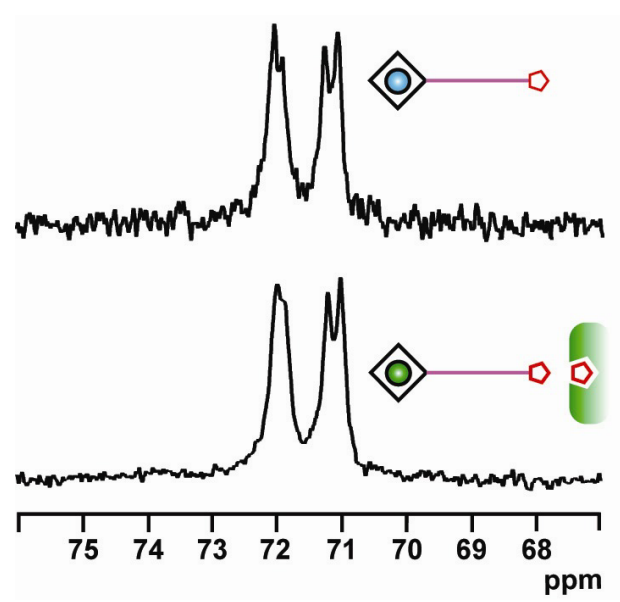

(A)

(B)

Figure 5. Effect of inhibiting the xenon biosensor binding to avidin. A. ${ }^{129}$ Xe spectrum from a solution of the biosensor alone $(300 \mu \mathrm{M})$; and B. after addition of approximately one-half equivalent of avidin $(180 \mu \mathrm{M})$ that was pre-equilibrated with a five-fold excess of biotin. These spectra show that the induced shift in Fig. 4 is from the specific binding of the biotinylated cage to avidin.

appearance of the down-field peak arises from specific binding of the biotin portion of the functionalized-xenon biosensor to avidin, rather than from nonspecific interactions with the protein. This also makes clear that specific binding of the biosensor to avidin is responsible for broadening of the functionalized-xenon resonances. The broad lines from the biosensor-protein complex have contributions from homogeneous broadening and the distribution of diasteromeric shifts.

\section{Exchange Measurements}

The biosensor-protein binding event may decrease the lifetime of xenon in the cage thereby making exchange linebroadening more efficient. To determine whether this was the case, the exchange rates were measured for both free and protein-bound biosensor.

The exchange of xenon between cage and solution was determined by measuring the recovery of selectively saturated functionalized-xenon signal. The pulse sequence used is shown in Figure 6a, in 


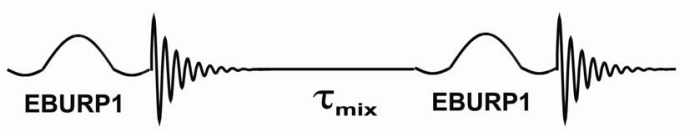

(A)

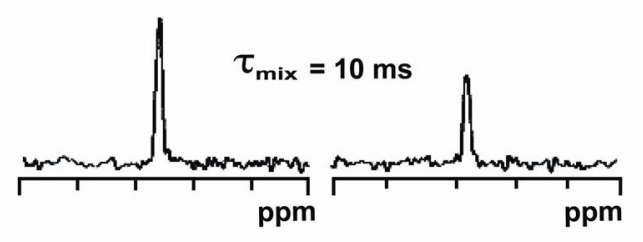

(B)

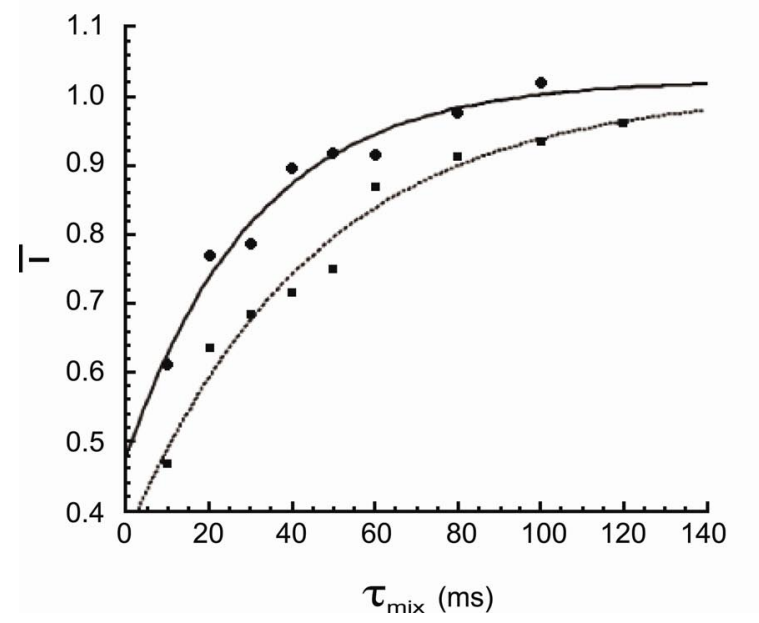

(C)

Figure 6: Comparison of xenon exchange with the biosensor cage when biosensor molecule is free ( $)$ and bound ( $\square$ ) to avidin. A. The pulse sequence for the measurement of the laser-polarized xenon exchange. The first pulse probes the magnetization of the functionalized xenon, and selectively saturates the resonance. After time $\tau_{\mathrm{ex}}$, the recovery of magnetization through exchange is probed by a second pulse. B. One pair of spectra showing magnetization recovery after $10 \mathrm{~ms}$. C. Magnetization recovery curves for $300 \mu \mathrm{M}$ biosensor / $360 \mu \mathrm{M}$ avidin solution ( $\mathbf{\square}$ ) and $300 \mu \mathrm{M}$ biosensor / $360 \mu \mathrm{M}$ biotin-saturated avidin solution $(\bullet)$ are shown with fitted exponential recovery curves.

which all pulses are $\sim 90^{\circ}$ chemical-shift-selective pulses centered on the resonance frequency of functionalized xenon as described in the experimental section. The initial observation of the $\mathrm{z}$ magnetization of the functionalized xenon is followed by an exchange delay, $\tau_{\operatorname{mix}}$, followed by another observation of the z-magnetization. The measurement of the signal intensity following the first pulse 
allows for the normalization of exchange-recovered intensity observed by the second pulse (Figure 6b). Without exchange, recovery of magnetization would be negligible as the equilibrium magnetization is small relative to the initial magnetization achieved with laser-polarization. The growth of magnetization during $\tau_{\text {mix }}$ occurs only through exchange with polarized xenon atoms in the solvent, allowing the rate to be determined via curve-fitting to a pseudo-first-order exchange mechanism, ${ }^{66}$ as shown in Figure 6c. This method presumes that a single saturation of the functionalized-xenon resonance does not significantly change the polarization of the xenon free in solution and that no significant spin-lattice relaxation of free xenon occurs between the first and second saturations. These are reasonable assumptions as free xenon is present in greater than 10-fold excess, and the spin-lattice relaxation time of free xenon in these solutions is on the order of hundreds of seconds, as measured by probing the longitudinal magnetization of the free xenon using tipping angles of $\sim 3^{\circ}$ at regular intervals (data not shown).

Figure $6 \mathrm{c}$ shows the data points and fits for exchange measurements of the free and avidin-bound functionalized-xenon solutions. The exchange lifetimes determined are $30 \pm 8 \mathrm{~ms}$ for free functionalized xenon and $45 \pm 11 \mathrm{~ms}$ for protein-bound functionalized xenon. The exchange lifetime for free functionalized xenon is consistent with the linewidth of $\sim 15 \mathrm{~Hz}$ observed in corresponding spectra suggesting that the exchange process is the dominant mechanism for linebroadening in the absence of protein. The similarity in exchange rate values for free and protein-bound biosensor indicates that increased broadening upon binding is not caused by an increase in the exchange rate of xenon between the cage and solvent. Thus, the broadening observed upon binding is most likely caused by the increase in rotational correlation time of the cage that dictates transverse $\left(T_{2}\right)$ relaxation time of xenon inside the cage. Binding of the biosensor molecule to a comparatively large protein should lengthen the correlation time of the cage considerably, leading to an increased efficiency of relaxation through dipole-dipole coupling and chemical shift anisotropy. Due to the high spin-polarization of ${ }^{129} \mathrm{Xe}$, significant xenon-to-proton cross-relaxation has been observed to protonated liquids, ${ }^{67}$ 
proteins, ${ }^{68,69}$ and also to cryptophane cage protons. ${ }^{70,71}$ Studies at different magnetic fields as well as studies with deuterated cages should help distinguish contributions from the two mechanisms.

Exchange rates comparable to those of xenon in the biosensor have been measured previously for xenon-cryptophane complexes in organic solutions at very low temperatures. ${ }^{65}$ In organic solvents at room temperature, cryptophane-A-bound xenon shows exchanged-broadened linewidths of hundreds of Hertz ${ }^{31}$ suggesting exchange rates more than an order of magnitude higher than those measured here. The slower exchange reflected in the narrower lines of the water-soluble xenon-cryptophane-A complex presented here suggest a higher binding constant of xenon in water than organic solvents, consistent with a larger hydrophobic contribution to the binding.

\section{Methods for Enhancing Biosensor Sensitivity}

In conventional-NMR signal averaging, individual scans are comprised of excitation, followed by acquisition and signal-recovery periods in which the magnetization is allowed to return toward thermal equilibrium. Experiments involving laser-polarized xenon are not amenable to this type of signal averaging because the large initial magnetization is non-equilibrium. Following the first acquisition, the xenon would relax back to its small, equilibrium polarization and subsequent scans would add negligible signal to the initial contribution of hyperpolarized xenon signal. Reestablishing the polarization requires adding more laser-polarized xenon to the sample, a substantial cost in experiment time.

Modified pulse sequences are often employed in laser-polarized xenon NMR spectroscopy and imaging to maximize use of the xenon magnetization. ${ }^{72,73}$ The exchange properties of the biosensor system presented here allow for the implementation of novel signal enhancement techniques using modified pulse sequences. The application of selective pulses is accomplished easily due to the large separation $(\sim 120 \mathrm{ppm})$ between xenon resonances in solution and in cages. The slow-exchange characteristic allows for the selective detection of free and functionalized xenon resonances by use of selective pulses to manipulate the two sets of spins independently. The exchange is relatively rapid in 
comparison to the longitudinal relaxation time of xenon, allowing for replenishment of biosensor-bound xenon polarization after saturation with little loss of signal between identical acquisitions. In the following sections we exploit these convenient exchange properties to increase biosensor sensitivity.

\section{Exchange Signal-Averaging}

Identification of a protein binding event by observation of a shift and broadening in the spectrum only requires the spectral region including the caged-xenon resonance and not that from xenon in the solvent. The cryptophane-bound xenon can be selectively excited using chemical-shift selective pulses. The polarization of xenon in the solvent is left to serve as a magnetization reservoir from which functionalized-xenon magnetization is replenished following an appropriate mixing time, $\tau_{\text {mix }}$. Repeat acquisitions of functionalized xenon spectra are added to result in a higher signal-to-noise spectrum. However, the magnetization of the xenon in solvent is a finite reservoir, limiting the number of spectra contributing a signal-to-noise enhancement to the average. Estimates of the bulk xenon $T_{1}$ value as well as the concentrations of both biosensor molecule and dissolved xenon allow an accurate calculation of how much averaging is beneficial. Figure 7a shows the pulse sequence used to accomplish exchange-

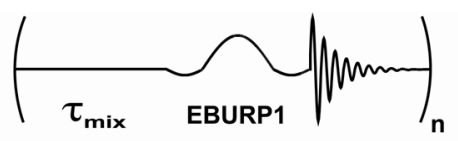

(A)

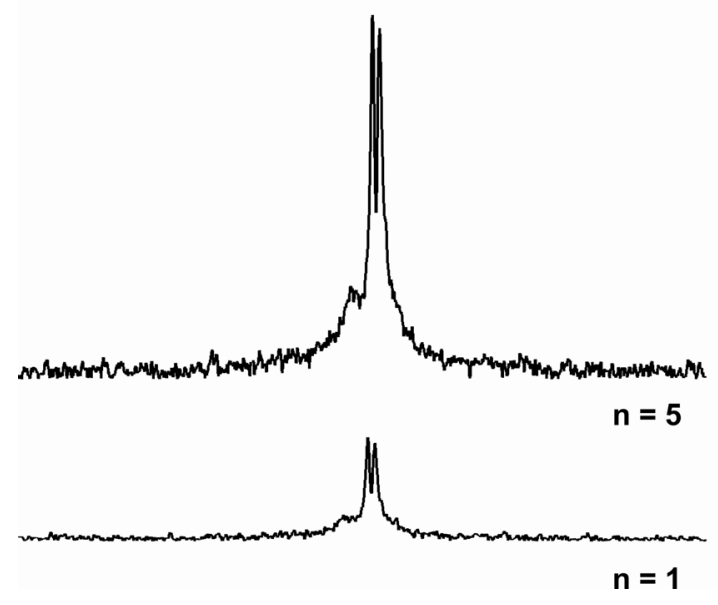

(B) 
Figure 7. A. A selective pulse centered about functionalized-xenon resonances is used to signal average functionalized-xenon peaks. Between selective saturations, the mixing time $\tau_{\operatorname{mix}}$ allows for the replenishment of functionalized-xenon signal by exchanging saturated spins with the polarized xenon dissolved in the surrounding solution. B. Two spectra of the functionalized-xenon peaks comparing one and five scans.

signal averaging. An example of signal-averaging is shown in Figure $7 \mathrm{~b}$ for five scans $(n=5)$. The signal-to-noise ratio has increased approximately by two-fold relative to the single scan spectrum because this number of scans has not significantly depleted the polarization reservoir in the solvent and $\mathrm{T}_{1}$ relaxation is negligible during course of the experiment.

Signal-averaging can afford a large sensitivity increase for xenon biosensor detection of dilute analytes, where the concentration of the analyte is much less than that of xenon in water. These averages can be repeated on the time scale of the magnetization exchange, tens of milliseconds, in contrast to the required relaxation delay for conventional signal averaging. Furthermore, the very large signal of xenon in water is not observed, eliminating the problem of dynamic range introduced by the coexistence of two signals of significantly different intensities, similar to that of proton NMR in the presence of water.

\section{Indirect Assay for Biosensor Event by Xenon Exchange}

In the simplest case, a xenon biosensor assay only requires relating a measurement of magnetization intensity to a quantity of protein-bound biosensor. This does not necessitate the acquisition of a functionalized xenon spectrum. Here we introduce a method, Figure 8a, that measures changes in the 

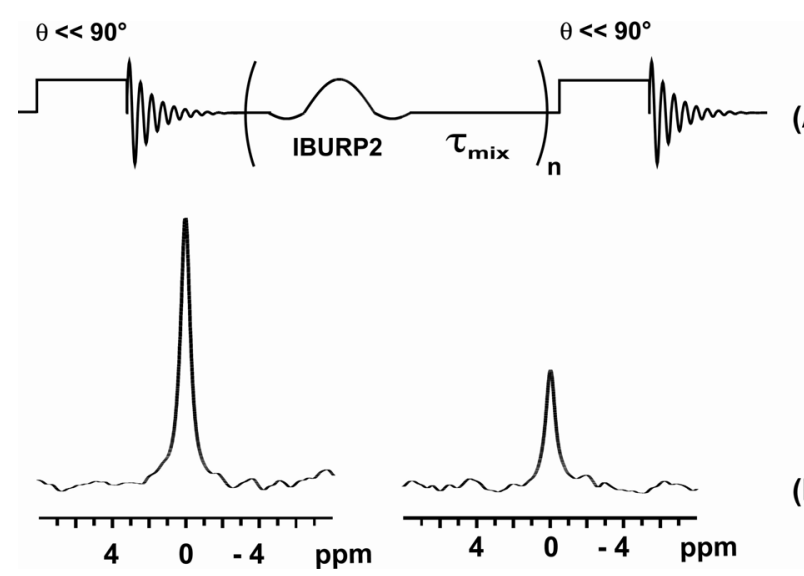

(B)

Figure 8. Indirect assay for peptide-derivatized cryptophane-A cage. A. A selective inversion pulse centered about the functionalized-xenon resonances is used to report the presence of functionalized xenon via a decrease in the xenon solution peak. Between selective inversions, the mixing time, $\tau_{\text {mix }}$, allows for the depletion of free-xenon signal by exchanging the negatively polarized spins from the cage with the positively polarized xenon that is dissolved in the surrounding solution. B. A spectrum of the xenon solution peak after the first broadband pulse (left) and a spectrum of the xenon solution peak after 5 selective inversion pulses $(n=5)$ and the second broadband pulse (right). The solution contained 1.5 mM peptide-derivatized cryptophane-A cage.

magnetization of free xenon in solution that are proportional to the amount of xenon biosensor. This method utilizes exchange of xenon between the functionalized and solvent environments to indirectly assay for the presence of xenon biosensor. Following a probe pulse (tip angle of $\sim 10^{\circ}$ ) to measure the initial magnetization of xenon in solution, multiple, selective inversions of functionalized-xenon magnetization are carried out to measurably reduce the magnetization of free xenon. An appropriate repetition rate of $\sim 5 \times \tau_{\mathrm{ex}}$ between inversion pulses allows the resulting, decreased magnetization of free xenon to directly reflect the amount of xenon biosensor, as measured by another probe pulse.

Figure $8 \mathrm{~b}$ shows the application of the indirect assay $(\mathrm{n}=5)$ to a solution containing $1.5 \mathrm{mM}$ of peptide-derivatized cryptophane-A cage (17). The decrease in the integrated intensity of the solution peak by $60 \%$ reflects the presence the cryptophane-bound xenon. Contributions to reduction in signal 
intensity from other factors including the initial tip pulse, $\mathrm{T}_{1}$ relaxation, and shaped pulse error were investigated. This was done by repeating the indirect assay with an off-resonance inversion pulse. The shaped pulse, which is normally centered about the functionalized xenon spins, is placed at an equal but opposite offset from the solution resonance. By mirroring the position of the shaped pulse, inversion of the biosensor magnetization is eliminated while maintaining an identical residual excitation of free xenon in both experiments. In addition, the delay between probe pulses $\left(\mathrm{n}=5 ; \tau_{\text {mix }}=150 \mathrm{~ms}\right)$ is unchanged in the off-resonance experiment allowing for equal $\mathrm{T}_{1}$ reduction in free xenon magnetization as compared to that of an on-resonance indirect assay. We found a $10 \%$ reduction in magnetization intensity after applying the off-resonance indirect assay pulse sequence, indicating the full reduction of signal intensity is associated with the presence of cryptophane-bound xenon.

The indirect assay for the xenon biosensor has sensitivity advantages over signal averaging. Its signal-to-noise ratio scales directly with the number of scans because the signal is acquired after the biosensor magnetization has accumulated. Unlike the functionalized-xenon signal, the observed solution-xenon signal not only scales with increasing laser-polarization, but also scales directly with the concentration of dissolved xenon. Hence, the limit of detection in terms of biosensor concentration is reduced. A full description of the application of this technique to quantitatively report and distinguish free and bound biosensor will be presented elsewhere.

\section{Conclusions}

The magnetic resonance properties of encapsulated xenon tethered to biotin, both free and bound to avidin, have been characterized. Detection of diastereomers by xenon has been reported for the first time and explains the presence of multiple lines observed in the functionalized xenon spectra. This suggests that the sensitivity of xenon to subtle changes in cage structure can be exploited to create sets of sensors that can be detected in parallel, thereby allowing for multiplexing at the chemical level. A full titration of the xenon biosensor with avidin is presented, showing a marked broadening of the xenon biosensor upon avidin binding. An increase in the xenon exchange rate was ruled out as a source of this 
broadening because the rate of xenon transfer is not significantly altered when the cage derivative binds to the protein. This rate is sufficiently slow that it does not contribute significantly to the linewidth of the protein-bound biosensor resonance. The broadening of the protein-bound functionalized xenon resonance results from an increase in the correlation time of the higher molecular weight complex through dipole-dipole and perhaps chemical shift anisotropy mechanisms. Asymmetrically hydroxylderivatized cryptophane-A cages termed cryptophanols, which were developed independently by Dutasta and co-workers, ${ }^{74}$ may also be used for the preparation of biosensor molecules. Dutasta and coworkers have also shown that cryptophanol-A cages can be partially deuterated, ${ }^{75}$ and use of these unique constructs in biosensor molecules should allow for experiments that distinguish the dipolar and CSA relaxation contributions to linebroadening of biosensor resonances. Particularly, reduction in the dipolar coupling by deuteration should improve the linewidth and sensitivity of biosensor experiments. Another approach that may reduce relaxation efficiency involves changing the length of the tether between the cage and biotin. A longer linker might allow more independent motion of the cryptophaneA cage, decreasing its correlation time and slowing xenon relaxation. In using this approach we must consider the possible reduction in the binding-induced shift response of the biosensor, if the shift mechanism depends on contact between the cage and protein. Recent theoretical studies by Sears and Jameson $^{64}$ have accurately modeled the response of xenon's chemical shift to a given cage structure by the careful averaging of different cage configurations sampled by the encapsulated xenon during an NMR experiment; consequently, it is possible that the chemical shift change of a long-linker biosensor arises from subtle distortions of the cage induced by changes in its vibrational and rotational motions, and this shift mechanism could still be effective even with a longer linker.

Signal enhancement using the exchange properties of the laser-polarized xenon biosensor was demonstrated to improve detection sensitivity. The techniques presented here are applicable to any system which binds xenon such that the exchange rate is slow on the chemical shift time scale, but fast on the spin-lattice relaxation time scale; a number cage molecules in the solid state and in solution show affinity and exchange properties for xenon. ${ }^{28-30,32,33}$ Exchange signal-enhancement of the xenon 
biosensor may extend its application to environments where analyte concentration is expected to be very

low, such as for in vivo spectroscopy and imaging. ${ }^{76}$ Moreover, it offers the possibility for even higher sensitivity remote detection.

\section{Acknowledgments}

The authors thank Robert A. Harris (for his indispensable role in the discovery of xenon detected diastereomer molecules), as well as Cynthia J. Jameson and Devin Sears for fruitful discussions regarding the diastereomeric chemical shifts of xenon. The authors thank Nycomed Amersham for sharing their knowledge of batch polarization techniques. M.M.S. and S.M.R. acknowledge the National Science Foundation and E.J.R. acknowledges Lucent Technologies/Bell Laboratories and UC Berkeley for pre-doctoral fellowships, N.W. acknowledges the National Institute of Health for his postdoctoral fellowship. This work was supported by the Director, Office of Science, Office of Basic Energy Sciences, Materials Sciences Division and Physical Biosciences Division of the U.S. Department of Energy under Contract No. DE-AC03-76SF00098. 


\section{References}

(1) Hogan, J. C. Nature 1996, 384, 17-19.

(2) Cawse, J. N. Accounts Chem Res 2001, 34, 213-221.

(3) Lehn, J. M.; Eliseev, A. V. Science 2001, 291, 2331-2332.

(4) Checovich, W. J.; Bolger, R. E.; Burke, T. Nature 1995, 375, 254-256.

(5) Broach, J. R.; Thorner, J. Nature 1996, 384, 14-16.

(6) Gauglitz, G. Curr Opin Chem Biol 2000, 4, 351-355.

(7) Khandurina, J.; Guttman, A. Curr Opin Chem Biol 2002, 6, 359-366.

(8) Cheung, V. G.; Morley, M.; Aguilar, F.; Massimi, A.; Kucherlapati, R.; Childs, G. Nat Genet 1999, 21, 15-19.

(9) Ziegler, C.; Gopel, W. Curr Opin Chem Biol 1998, 2, 585-591.

(10) Keusgen, M. Naturwissenschaften 2002, 89, 433-444.

(11) Malmqvist, M. Nature 1993, 361, 186-187.

(12) Johnston, K. S.; Mar, M.; Yee, S. S. Sensor Actuat B-Chem 1999, 54, 57-65.

(13) Shuker, S. B.; Hajduk, P. J.; Meadows, R. P.; Fesik, S. W. Science 1996, 274, 15311534.

(14) Keifer, P. A. Curr Opin Biotech 1999, 10, 34-41.

(15) Lacey, M. E.; Subramanian, R.; Olson, D. L.; Webb, A. G.; Sweedler, J. V. Chem Rev 1999, 99, 3133-3152.

(16) Shapiro, M. J.; Gounarides, J. S. Prog Nucl Mag Res Sp 1999, 35, 153-200.

(17) Olson, D. L.; Peck, T. L.; Webb, A. G.; Magin, R. L.; Sweedler, J. V. Science 1995, 270, 1967-1970.

(18) Hou, T.; Smith, J.; MacNamara, E.; Macnaughtan, M.; Raftery, D. Anal Chem 2001, 73, 2541-2546.

(19) Happer, W. Rev Mod Phys 1972, 44, 169-249.

(20) Walker, T. G.; Happer, W. Rev Mod Phys 1997, 69, 629-642.

(21) Zook, A. L.; Adhyaru, B. B.; Bowers, C. R. J Magn Reson 2002, 159, 175-182.

(22) Moule, A. J.; Spence, M. M.; Han, S. I.; Seeley, J. A.; Pierce, K. L.; Saxena, S.; Pines, A. P Natl Acad Sci USA 2003, 100, 9122-9127.

(23) Seeley, J. A.; Han, S. I.; Pines, A. J Magn Reson 2003, 167, 282-290.

(24) Ripmeester, J. A.; Ratcliffe, C. I.; Tse, J. S. J Chem Soc Farad T 1 1988, 84, 3731-3745. 
(25) Chmelka, B. F.; Raftery, D.; Mccormick, A. V.; Demenorval, L. C.; Levine, R. D.; Pines, A. Phys Rev Lett 1991, 66, 580-583.

(26) Springuel-Huet, M. A.; Bonardet, J. L.; Gedeon, A.; Fraissard, J. Magn Reson Chem 1999, 37, S1-S13.

(27) Sozzani, P.; Comotti, A.; Simonutti, R.; Meersmann, T.; Logan, J. W.; Pines, A. Angew Chem Int Edit 2000, 39, 2695-2698.

(28) Cram, D. J.; Tanner, M. E.; Knobler, C. B. J Am Chem Soc 1991, 113, 7717-7727.

(29) Bartik, K.; Luhmer, M.; Heyes, S. J.; Ottinger, R.; Reisse, J. J Magn Reson Ser B 1995, $109,164-168$.

(30) Branda, N.; Grotzfeld, R. M.; Valdes, C.; Rebek, J. J Am Chem Soc 1995, 117, 85-88.

(31) Bartik, K.; Luhmer, M.; Dutasta, J. P.; Collet, A.; Reisse, J. J Am Chem Soc 1998, 120, 784-791.

(32) Syamala, M. S.; Cross, R. J.; Saunders, M. J Am Chem Soc 2002, 124, 6216-6219.

(33) El Haouaj, M.; Luhmer, M.; Ko, Y. H.; Kim, K.; Bartik, K. J Chem Soc Perk T 2 2001, 804-807.

(34) Song, Y. Q.; Goodson, B. M.; Taylor, R. E.; Laws, D. D.; Navon, G.; Pines, A. Angewandte Chemie-International Edition in English 1997, 36, 2368-2370.

(35) Albert, M. S.; Cates, G. D.; Driehuys, B.; Happer, W.; Saam, B.; Springer, C. S.; Wishnia, A. Nature 1994, 370, 199-201.

(36) Albert, M. S.; Schepkin, V. D.; Budinger, T. F. J Comput Assist Tomo 1995, 19, 975-978.

(37) Albert, M. S.; Balamore, D. Nucl Instrum Meth A 1998, 402, 441-453.

(38) Cherubini, A.; Bifone, A. Prog Nucl Mag Res Sp 2003, 42, 1-30.

(39) Goodson, B. M. J Magn Reson 2002, 155, 157-216.

(40) Miller, K. W.; Reo, N. V.; Uiterkamp, A. J. M. S.; Stengle, D. P.; Stengle, T. R.; Williamson, K. L. P Natl Acad Sci-Biol 1981, 78, 4946-4949.

(41) Tilton, R. F.; Kuntz, I. D. Biochemistry-Us 1982, 21, 6850-6857.

(42) Rubin, S. M.; Spence, M. M.; Goodson, B. M.; Wemmer, D. E.; Pines, A. P Natl Acad Sci USA 2000, 97, 9472-9475.

(43) Locci, E.; Dehouck, Y.; Casu, M.; Saba, G.; Lai, A.; Luhmer, M.; Reisse, J.; Bartik, K. J Magn Reson 2001, 150, 167-174.

(44) Rubin, S. M.; Spence, M. M.; Dimitrov, I. E.; Ruiz, E. J.; Pines, A.; Wemmer, D. E. J Am Chem Soc 2001, 123, 8616-8617.

(45) Rubin, S. M.; Lee, S. Y.; Ruiz, E. J.; Pines, A.; Wemmer, D. E. J Mol Biol 2002, 322, 425-440.

(46) Bowers, C. R.; Storhaug, V.; Webster, C. E.; Bharatam, J.; Cottone, A.; Gianna, R.; Betsey, K.; Gaffney, B. J. J Am Chem Soc 1999, 121, 9370-9377. 
(47) Mckim, S.; Hinton, J. F. Bba-Biomembranes 1994, 1193, 186-198.

(48) Xu, Y.; Tang, P. Bba-Biomembranes 1997, 1323, 154-162.

(49) Schiltz, M.; Prange, T.; Fourme, R. J Appl Crystallogr 1994, 27, 950-960.

(50) Soltis, S. M.; Stowell, M. H. B.; Wiener, M. C.; Phillips, G. N.; Rees, D. C. J Appl Crystallogr 1997, 30, 190-194.

(51) Spence, M. M.; Rubin, S. M.; Dimitrov, I. E.; Ruiz, E. J.; Wemmer, D. E.; Pines, A.; Yao, S. Q.; Tian, F.; Schultz, P. G. P Natl Acad Sci USA 2001, 98, 10654-10657.

(52) Han, M. Y.; Gao, X. H.; Su, J. Z.; Nie, S. Nat Biotechnol 2001, 19, 631-635.

(53) Nicewarner-Pena, S. R.; Freeman, R. G.; Reiss, B. D.; He, L.; Pena, D. J.; Walton, I. D.; Cromer, R.; Keating, C. D.; Natan, M. J. Science 2001, 294, 137-141.

(54) Geen, H.; Freeman, R. J Magn Reson 1991, 93, 93-141.

(55) Collet, A. Tetrahedron 1987, 43, 5725-5759.

(56) Brotin, T.; Devic, T.; Lesage, A.; Emsley, L.; Collet, A. Chem-Eur J 2001, 7, 1561-1573.

(57) Kilenyi, S. N.; Mahaux, J. M.; Vandurme, E. J Org Chem 1991, 56, 2591-2594.

(58) Bartik, K.; El Haouaj, M.; Luhmer, M.; Collet, A.; Reisse, J. Chemphyschem 2000, 1, 221-224.

(59) Bartik, K.; Luhmer, M.; Collet, A.; Reisse, J. Chirality 2001, 13, 2-6.

(60) Sears, D. N.; Jameson, C. J.; Harris, R. A. Journal of Chemical Physics 2003, 119, $2685-$ 2690.

(61) Sears, D. N.; Jameson, C. J.; Harris, R. A. Journal of Chemical Physics 2003, 119, 26912693.

(62) Sears, D. N.; Jameson, C. J.; Harris, R. A. Journal of Chemical Physics 2003, 119, 26942701. 3283.

(63) Sears, D. N.; Jameson, C. J.; Harris, R. A. Journal of Chemical Physics 2004, 120, 3277-

(64) Sears, D. N.; Jameson, C. J. Journal of Chemical Physics 2003, 119, 12231-12244.

(65) Brotin, T.; Lesage, A.; Emsley, L.; Collet, A. J Am Chem Soc 2000, 122, 1171-1174.

(66) Mcconnell, H. M. Journal of Chemical Physics 1958, 28, 430-431.

(67) Navon, G.; Song, Y. Q.; Room, T.; Appelt, S.; Taylor, R. E.; Pines, A. Science 1996, $271,1848-1851$. 332.

(68) Berthault, P.; Landon, C.; Vovelle, F.; Desvaux, H. Cr Acad Sci Iv-Phys 2001, 2, 327-

(69) Landon, C.; Berthault, P.; Vovelle, F.; Desvaux, H. Protein Sci 2001, 10, 762-770.

(70) Luhmer, M.; Goodson, B. M.; Song, Y. Q.; Laws, D. D.; Kaiser, L.; Cyrier, M. C.; Pines, A. J Am Chem Soc 1999, 121, 3502-3512. 
(71) Desvaux, H.; Huber, J. G.; Brotin, T.; Dutasta, J. P.; Berthault, P. Chemphyschem 2003, 4, 384-387.

(72) Patyal, B. R.; Gao, J. H.; Williams, R. F.; Roby, J.; Saam, B.; Rockwell, B. A.; Thomas, R. J.; Stolarski, D. J.; Fox, P. T. J Magn Reson 1997, 126, 58-65.

(73) Ruppert, K.; Brookeman, J. R.; Hagspiel, K. D.; Mugler, J. P. Magnet Reson Med 2000, $44,349-357$.

(74) Darzac, M.; Brotin, T.; Bouchu, D.; Dutasta, J. P. Chem Commun 2002, 48-49.

(75) Darzac, M.; Brotin, T.; Rousset-Arzel, L.; Bouchu, D.; Dutasta, J. P. New. J. Chem (In Press) 2004.

(76) Lowery, T. J.; Rubin, S. M.; Ruiz, E. J.; Spence, M. M.; Winssinger, N.; Schultz, P. G.; Pines, A.; Wemmer, D. E. Magn Reson Imaging 2003, 21, 1235-1239. 
Table of Contents Figure

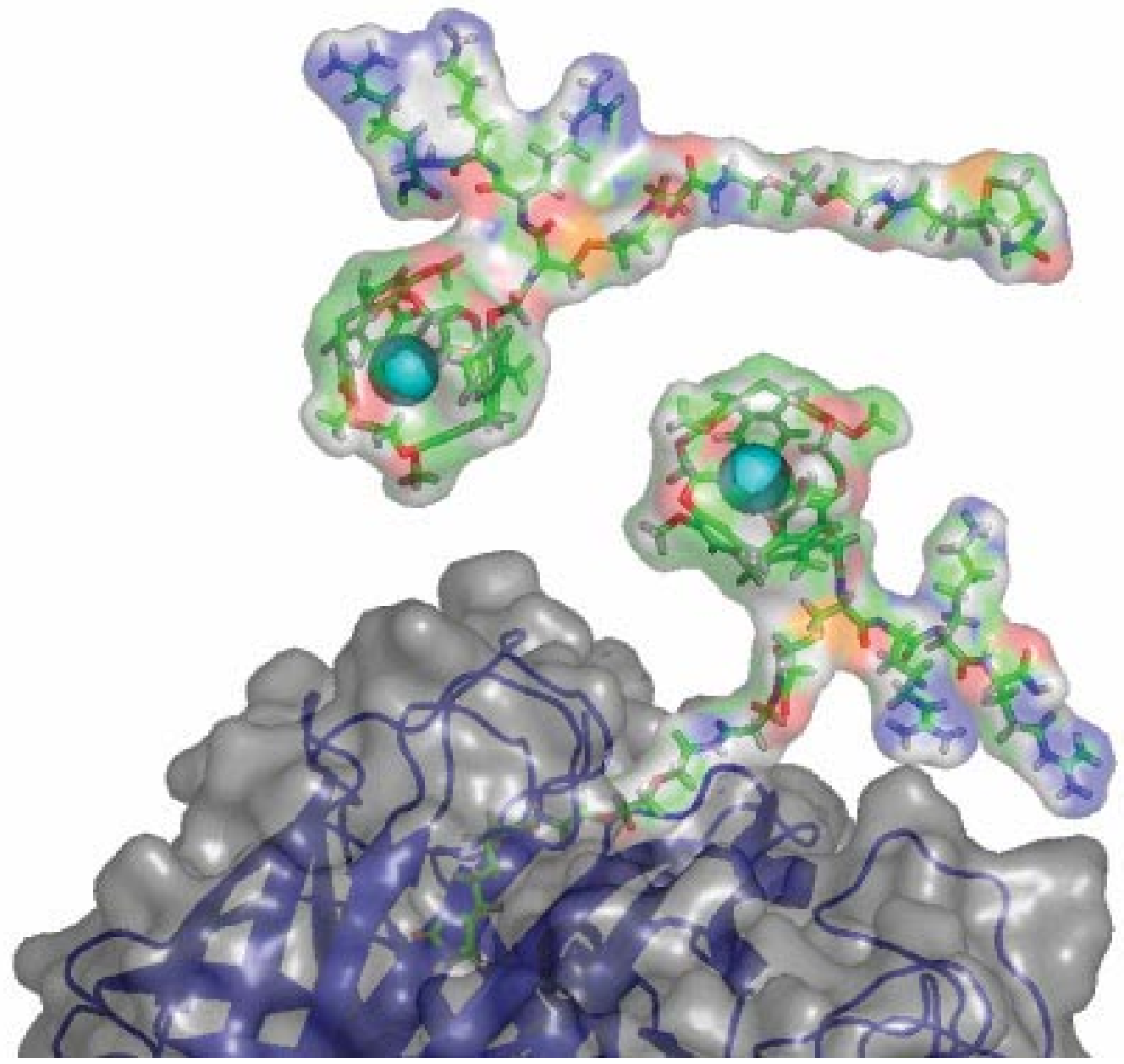

